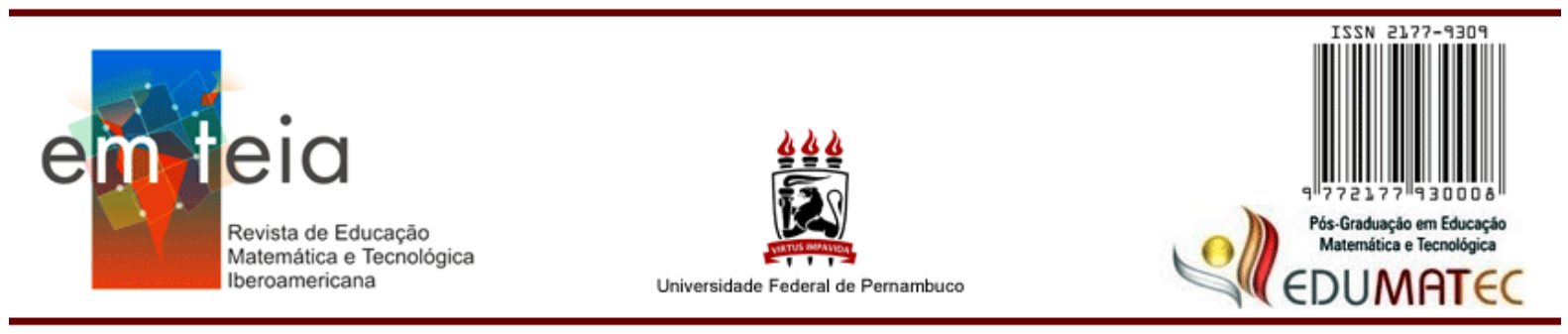

\title{
PERCEPÇÃO DAS PESSOAS DA TERCEIRA IDADE: habilidades e uso das tecnologias digitais
}

\author{
Maria Amélia Silva \\ mmelasilva@gmail.com \\ Thelma Panerai Alves \\ tpanerai@gmail.com
}

\section{Resumo}

Este artigo é um recorte da dissertação de mestrado intitulada "Habilidades desenvolvidas pelas pessoas da terceira idade: inclusão digital e uso de smartphone", do Programa de Educação Matemática e Tecnológica (Edumatec), da Universidade Federal de Pernambuco (UFPE). O estudo teve por objetivo verificar a percepção das pessoas da terceira idade sobre as habilidades digitais necessárias para sua inserção na cultura digital, pois a literatura sobre o tema mostra que, para essas pessoas, o uso das tecnologias digitais pode apresentar algumas dificuldades. Fundamentaram nosso estudo Araújo (2019), Kachar (2003), Perrenoud (1999, 2013), Kenski (2012) e Lemos (2009). Para essa pesquisa, adotamos uma metodologia de natureza qualitativa, com caráter descritivo. Para isso, utilizamos como instrumento de coleta de dados uma entrevista semiestruturada. $\mathrm{Na}$ análise dos dados, usamos a técnica da Análise de Conteúdo. Responderam a entrevista 7 pessoas da terceira idade. Quanto aos resultados da pesquisa, destacamos que a percepção de habilidades digitais, pelas pessoas da terceira idade, está relacionada à maneira de usar a tecnologia, ao saber fazer. Consideramos que a percepção das habilidades digitais para os participantes da pesquisa vai além de conhecer a técnica para o manuseio das tecnologias.

Palavras-Chave: Habilidades. Tecnologias digitais. Percepção. Terceira Idade. Cultura digital.

\begin{abstract}
This article is an excerpt from the master's thesis entitled Skills developed by the elderly: digital inclusion and use of smartphones, from the Mathematical and Technological Education Program (Edumatec), from the Federal University of Pernambuco (UFPE). The study aimed at verifying the perception of elderly people about the digital skills necessary for their insertion in digital culture, as the literature on the subject shows that, for these people, the use of digital technologies can present some difficulties. Our study was based on Araújo (2019), Kachar (2003), Perrenoud (1999, 2013), Kenski (2012) and Lemos (2009). The methodology used was a qualitative research of a descriptive nature. We used a semi-structured interview as the instrument of data collection and 7 (seven) elderly people were the respondents. The information collected was analyzed through the Content Analysis. The results of the research show that the perception of digital skills by the elderly is related to the way they use technology: on knowing how to do it. We believe that the perception of digital skills by the participants in this research is not restricted to knowing the technique for using technologies.
\end{abstract}

Keywords: Skills. Digital Technologies. Perception. Third Age. Digital inclusion. 


\section{Introdução}

O Relatório da Unesco (2015) sintetiza como a Educação para o século XXI deve desenvolver habilidades nos indivíduos para que eles saibam lidar com as novas tecnologias, constituindo-se num desafio para o processo de construção da cultura. Esse relatório também reconhece que, além das habilidades cognitivas, é necessário construir valores e habilidades socioemocionais e comportamentais.

Com foco nas habilidades, a Base Nacional Comum Curricular (BNCC) considera a necessidade de valorizar e utilizar a prática do saber fazer em relação aos conhecimentos, incluindo nisso o universo digital.

A expansão das tecnologias digitais na sociedade provoca transformações sociais importantes e, no que se refere às pessoas da terceira idade, o uso das tecnologias digitais ganhou novos sentidos. Essa expansão pode favorecer a qualidade de vida e a longevidade das pessoas idosas, embora muitas delas já apresentem dificuldades motoras e cognitivas impostas pelo envelhecimento e, com isso, possam ser excluídas do mundo digital.

As habilidades, que podem ser entendidas como elementos da competência, estabelecem relação com os outros diferentes componentes que constituem essa competência (PERRENOUD, 1999, 2013). E, neste sentido, a necessidade de desenvolvimento das habilidades digitais, para a inserção das pessoas da terceira idade na cultura digital, tem revelado que elas podem apresentar dificuldades em lidar com os avanços tecnológicos (KACHAR, 2003).

Kachar (2003) enfatiza a importância das pessoas de mais idade estarem conectadas às tecnologias digitais. $\mathrm{O}$ acesso ao universo digital possibilita novas formas de comunicação com parentes, amigos e pessoas do mundo inteiro. Deste modo, a utilização de dispositivos digitais e táteis, como o smartphone, por exemplo, poderá auxiliar essas pessoas a se integrarem mais facilmente em diferentes contextos.

A interação realizada por meio das tecnologias digitais pode despertar diversas percepções relativas à necessidade de desenvolvimento de habilidades digitais nessa fase da vida. Isso se deve ao fato de que o desenvolvimento de habilidades digitais permite formas diferentes de pensar e processar informações, nos mais diversos tipos de linguagens, favorecendo a independência das pessoas.

Deste modo, a percepção da necessidade do desenvolvimento de habilidades digitais pela terceira idade pode facilitar a relação desses indivíduos com as tecnologias. 


\section{Percepção, terceira idade e tecnologias digitais}

Com a revolução tecnológica e as melhorias nas condições de vida da sociedade, observamos um aumento da longevidade da população. Os dados do Instituto Brasileiro de Geografia e Estatística (IBGE, 2018) demostram que a expectativa de vida da população brasileira aumentou de 73,86 anos, em 2010, para 76,25 em 2018. Isso indica um aumento significativo de pessoas com mais de 60 anos, no Brasil.

A esse respeito, o Estatuto do Idoso, Lei $\mathrm{n}^{\circ}$ 10.741, afirma que "Rapidamente, deixamos de ser um "país de jovens" e o envelhecimento tornou-se questão fundamental para as políticas públicas" (BRASIL, 2003, p. 5).

Sabemos que o processo de envelhecimento repercute em toda a sociedade, mesmo que seja um processo espontâneo e natural. Neste contexto, o conceito de velhice tem se modificado nos últimos anos e ganha outra dimensão com a expressão terceira idade. Para Debert (2011), essa expressão surge para representar os aposentados que se mostram ativos e independentes na sociedade. Ou seja, a percepção de que o aposentado veste seu pijama e tem sua participação cidadã reduzida parece ter ficado para trás.

Portanto, com o aumento da expectativa de vida, as pessoas da terceira idade podem se deparar com novas experiências cognitivas, psicomotoras e afetivas, que favoreçam o desenvolvimento de novos saberes e que proporcionem emoções singulares.

Dentro desta visão, Almeida (2007, p. 48, apud GANDRA, 2012, p. 74) afirma que a "percepção da nossa situação sempre nos é desvelada antes pelos sentimentos do que pelo conhecimento". E é neste sentido que, através das emoções, o indivíduo é capaz de perceber e de valorizar as novas oportunidades que surgem diante de si.

Para Morin (2011, p. 20), “as percepções são, ao mesmo tempo, traduções e reconstruções cerebrais com base em estímulos ou sinais captados e codificados pelos sentidos", ou seja, o conhecimento é sempre uma tradução e uma reconstrução por meio do pensamento e não apenas pelo reflexo do mundo externo.

Kachar (2003, p. 42) afirma que, nas alterações nas funções de percepção, "mesmo no envelhecimento normal há usualmente uma percepção subjetiva de declínio na habilidade em adquirir e recordar informações". Isso indica que a percepção envolve também processos mentais relacionados à cognição e à memória que podem influenciar na interpretação da realidade.

Dessa maneira, neste estudo, tomaremos como base que a percepção vai além de atribuir significado às experiências visuais, ou seja, "tais experiências só se configuram como 
uma percepção se suas condições de satisfação forem atendidas, do contrário, diremos que se trata de uma experiência visual" (ARAÚJO, 2019, p. 85). No decorrer da interação com as tecnologias, cada pessoa compreende de forma diferente os significados, não de forma isolada “em relação com outros objetos e estados de coisas no mundo" (ARAÚJO, 2019, p. 157), mas a partir das diferentes experiências vivenciadas e realidade de cada indivíduo.

Para Kachar (2003, p. 52), "a geração dos idosos de hoje tem revelado suas dificuldades em entender a nova linguagem e em lidar com os avanços tecnológicos até mesmo nas questões mais básicas como os eletrodomésticos, celulares e os caixas eletrônicos instalados nos bancos". Então, nesta realidade, há um grande desafio a ser enfrentado: favorecer que as pessoas da terceira idade utilizem as interfaces digitais para realizar seus interesses pessoais, sem precisar de outras pessoas para lidar com os comandos cada vez mais sofisticados e suas versões atualizadas. Sobre isso, Kenski (2012) considera que é necessário aprender a utilizar as tecnologias e a se relacionar com elas, para que estas possam ser incorporadas ao universo de conhecimentos e habilidades de cada pessoa.

Em relação às habilidades, Perrenoud (2013, p. 48) afirma que são "como esquemas que orientam as operações mentais e as operações concretas". No entanto, este autor ressalta que as habilidades como saber ler, contar, medir, classificar, pesquisar etc., sozinhas, não bastam para resolver situações.

É preciso saber que as habilidades estão associadas ao saber fazer: ação física ou mental que indica a capacidade adquirida. Assim, identificar variáveis, compreender fenômenos, relacionar informações, analisar situações-problema, sintetizar, julgar correlacionar e manipular são exemplos de habilidades. Logo, habilidade refere-se basicamente a capacidade e a disposição para (fazer) algo (SILVA; KALHIL, 2017, p. 71).

A percepção sobre essas habilidades se traduz na capacidade de lidar com as tecnologias digitais para fazer algo. Deste modo, com base nesses enfoques, abordaremos as habilidades digitais como os processos técnicos referentes ao uso das tecnologias digitais, tais como: digitar, navegar, acessar etc.

Diante disso, acreditamos que a inserção das pessoas da terceira idade no mundo digital pode possibilitar ao indivíduo ampliar o acesso à informação, adquirindo novas práticas culturais ligadas à busca e à construção do conhecimento. Igualmente importantes são as interações e novas formas de comunicação com familiares, conhecidos e desconhecidos do mundo inteiro. Ou seja, saber utilizar as tecnologias digitais, além de favorecer o acesso às informações e à ampliação do conhecimento, melhora a qualidade de vida e a interação social das pessoas de mais idade. Com essas novas práticas e com a inserção em ambientes digitais, 
que Lemos (2009) chama de cultura digital, uma nova forma de obter e produzir informação é criada. Ou seja, vivemos em uma "cultura contemporânea, onde os diversos dispositivos eletrônicos digitais já fazem parte da nossa realidade" (LEMOS, 2009, p. 136).

Nesta realidade, diferente dos que nasceram mergulhados na cultura digital e cresceram usando internet, tablets e celulares e/ou smartphone, algumas pessoas da terceira idade podem perceber com reservas as novas linguagens, nos novos suportes.

Para Cazeloto (2008), é necessário refletir sobre o uso que pode ser dado às tecnologias. Neste sentido, não basta só saber utilizar as tecnologias, mas também é preciso considerar as oportunidades sociais coletivas dos indivíduos, visto que, muitas vezes, as informações chegam de forma diferente para cada pessoa.

Assim, o domínio das tecnologias digitais pode contribuir para que as pessoas da terceira idade se tornem mais independentes e motivadas. Kachar (2003) assinala que o uso desses recursos pode melhorar a qualidade de vida delas em diversos aspectos, tornando-se, muitas vezes, interfaces de resgate à autoestima. Isso é bastante significativo, considerando que essas pessoas podem vivenciar momentos de interação e lazer tão intensos, com o uso de tecnologias digitais, quanto os momentos que vivenciam cara-a-cara.

\section{Percurso metodológico}

No presente artigo, apresentamos um recorte dos dados de uma pesquisa de mestrado, que analisou as habilidades digitais desenvolvidas pelas pessoas da terceira idade para sua inclusão na cultura digital, na Universidade Aberta à Terceira Idade (UnATI), da Universidade Federal de Pernambuco (UFPE).

Optamos por realizar uma pesquisa qualitativa, com caráter descritivo, para podermos interpretar o universo escolhido em seu ambiente natural, descrevendo as características dos sujeitos e de suas experiências.

A pesquisa obedeceu aos preceitos éticos da Resolução 466/12 ou 510/16 do Conselho Nacional de Saúde (CNS) considerados em pesquisas envolvendo seres humanos. Após a autorização da pesquisa pelo Comitê de Ética em Pesquisa (CEP) e autorização dos participantes, através do Termo de Consentimento Livre e Esclarecido (TCLE), foi possível iniciar a pesquisa com o auxílio do instrumento de coleta de dados utilizado neste artigo: a entrevista.

Para evitar constrangimentos aos participantes da pesquisa no momento de responderem às questões, realizamos a coleta de dados individualmente. Com relação aos riscos de identificação do 
nome ou informações do participante, optamos por não coletar nomes e contatos dos participantes.

Definimos a idade equivalente ou superior a 60 anos como critério de inclusão/participação na pesquisa; como critério de exclusão, definimos a nãodisponibilidade para responder às questões da entrevista.

O campo específico de pesquisa foram as aulas do curso sobre inclusão digital, com as 10 pessoas da terceira idade matriculadas regularmente no referido curso.

Dessa forma, estabelecemos um roteiro prévio referente à percepção das pessoas da terceira idade sobre as habilidades digitais necessárias para sua inclusão na cultura digital, tendo por finalidade dar voz aos participantes da pesquisa que demonstrassem interesse em participar da entrevista. O roteiro da entrevista, apresentado a seguir, foi o mesmo para todos os participantes:

- O que você entende por habilidades digitais?

- Na sua opinião, quais as habilidades digitais que a pessoa da terceira idade deveria desenvolver no curso para utilizar o smartphone?

- Quais as principais dificuldades/problemas para utilizar o smartphone?

- Você tem recebido ajuda dos familiares ou amigos em relação ao uso do smartphone?

- Você considera que o uso das tecnologias digitais tem ajudado a resolver situações/problemas em seu cotidiano? Qual/quais?

- O que você pensa sobre inclusão digital na terceira idade?

- Você se considera uma pessoa incluída digitalmente, na sociedade? Por quê?

Realizamos as entrevistas utilizando um gravador de voz, por meio do aparelho celular, como recurso para gravar as entrevistas realizadas, que aconteceram (Tabela 1) no período entre 20 de maio e 18 de junho de 2019, de acordo com a vontade e disponibilidade de cada participante. Observamos na Tabela 1 que, dos 10 participantes, apenas 7 se disponibilizaram a participar da entrevista.

Tabela 1 - Quantitativo de entrevistas aplicadas aos participantes da pesquisa Instrumento Participantes Entrevistados

Entrevista 10 7

Fonte: Elaboração própria, 2019.

Após a coleta dos dados, as respostas das entrevistas foram categorizadas e analisadas na perspectiva da Análise de Conteúdo por constituir "uma metodologia de pesquisa usada para descrever e interpretar o conteúdo de toda a classe de documentos e texto" (MORAES, 1999, p. 9), ou seja, considera as condições contextuais de seus participantes para compreender além de seus significados. 
Nessa perspectiva, a análise dos dados procurou responder ao objetivo de verificar a percepção das pessoas da terceira idade sobre as habilidades digitais necessárias para sua inclusão na cultura digital.

Conforme apresentado anteriormente, participaram da entrevista 7 pessoas da terceira idade, sendo 6 do gênero feminino e 1 do masculino. Nessa amostra, o curso é essencialmente frequentado por mulheres aposentadas.

A amostra foi distribuída nas seguintes faixas etária (Tabela 2).

Tabela 2 - Faixa etária dos participantes da pesquisa

\begin{tabular}{cccc}
\hline 60 & Mais de & Mais de & Mais de \\
$\mathbf{6 n o s}$ & $\mathbf{6 0}$ anos & $\mathbf{7 0}$ anos & $\mathbf{8 0}$ anos \\
\hline 0 & 5 & 4 & 1 \\
\hline
\end{tabular}

Fonte: Elaboração própria, 2019.

A seguir, passamos a discutir a análise dos dados e os resultados da pesquisa buscando relacioná-los com o contexto descrito.

\section{Resultados e discussão}

Após a categorização/classificação das unidades de análise, adotamos códigos constituídos por letras (TI, que corresponde à Terceira Idade) e números $(1,2 \ldots 7$, que corresponde à ordem das respostas), identificando as respostas dos participantes (TI1, TI2... TI3, sucessivamente). Incluímos também no roteiro das entrevistas questões sobre perspectiva de inclusão digital para discutir sobre habilidades digitais e essa inclusão. Dessa forma, nesse artigo, destacamos como categorias: Saber fazer e Pertencimento. No que se refere às subcategorias, elas foram definidas com base nas unidades de contexto.

Quando questionados sobre o entendimento das habilidades digitais necessárias para sua inclusão na cultura digital (Quadro 1), os participantes responderam:

Quadro 1 - Percepção de habilidades digitais pelos participantes da pesquisa

\begin{tabular}{|l|l|l|l|l|}
\hline \multicolumn{1}{|c|}{$\begin{array}{c}\text { Objetivo } \\
\text { Específico }\end{array}$} & Categoria & Subcategorias & $\begin{array}{c}\text { Unidades de } \\
\text { Registro }\end{array}$ & \multicolumn{1}{c|}{$\begin{array}{c}\text { Unidades de } \\
\text { Contexto }\end{array}$} \\
\hline $\begin{array}{l}\text { Verificar a } \\
\text { percepção das } \\
\text { pessoas da } \\
\text { terceira idade }\end{array}$ & Saber fazer & Aprendizagem & Mundo & $\begin{array}{l}\text { "Eu acho que é a pessoa se conectar } \\
\text { com o mundo, não é? (...) Acessar essa } \\
\text { rede para se comunicar com o mundo, } \\
\text { acho que isso é uma habilidade” (TI1) }\end{array}$ \\
\hline
\end{tabular}




\begin{tabular}{|c|c|c|c|}
\hline \multirow[t]{5}{*}{$\begin{array}{l}\text { sobre as } \\
\text { habilidades } \\
\text { digitais } \\
\text { necessárias } \\
\text { para sua } \\
\text { inclusão na } \\
\text { cultura digital }\end{array}$} & \multirow[t]{5}{*}{$\begin{array}{l}\text { Interação } \\
\text { social/ } \\
\text { Comunicação }\end{array}$} & \multirow[t]{5}{*}{$\begin{array}{l}\text { Aprender } \\
\text { Conhecer o } \\
\text { aparelho }\end{array}$} & $\begin{array}{l}\text { "Justamente eu estou aqui para } \\
\text { aprender, visse, sei um pouquinho } \\
\text { ligar e desligar, no tablet ainda não } \\
\text { sei. (...) Ligo, desligo, no Zap já mando } \\
\text { mensagem, recebo mensagem, agora } \\
\text { as outras coisas ainda tô aprendendo" } \\
\text { (TI2) }\end{array}$ \\
\hline & & & $\begin{array}{l}\text { "Habilidade digital pra mim é você, } \\
\text { como é que se diz, ter intimidade com } \\
\text { aquele aparelho, você saber } \\
\text { exatamente o que ele pode te dar de } \\
\text { informação. É você saber utilizá-lo } \\
\text { com precisão (...)” (TI3) }\end{array}$ \\
\hline & & & $\begin{array}{l}\text { Pra mim é conhecer o aparelho, } \\
\text { conhecer esse grande mistério desse } \\
\text { mundo digital, porque é muito } \\
\text { complexo" (TI4) }\end{array}$ \\
\hline & & & $\begin{array}{l}\text { "Hoje em dia isso é prioridade, mas aí } \\
\text { eu acho que a gente tem que se } \\
\text { encaixar agora e não ficar pra trás, } \\
\text { tão pra trás, acho que a gente tem que } \\
\text { aprender alguma coisa para não ficar } \\
\text { tão no passado, é por isso" (TI5) }\end{array}$ \\
\hline & & & $\begin{array}{l}\text { "Eu acho importante porque é uma } \\
\text { habilidade prática e rápida para } \\
\text { comunicação né” (TI7) }\end{array}$ \\
\hline
\end{tabular}

Fonte: Elaboração própria, 2019.

Observamos, no Quadro 1, a partir das unidades de registros que aparecem nas falas dos participantes, que a percepção de habilidades digitais sugere acompanhar as tecnologias criando um elo com o mundo digital, como podemos verificar em algumas falas:

"Eu acho que é a pessoa se conectar com o mundo, não é? (...)” (TI1)

“(...) conhecer esse grande mistério desse mundo digital, porque é muito complexo." (TI4)

Verificamos que a comunicação/comunicar aparece nas falas mostrando que as habilidades digitais também estão relacionadas ao fato de interagir com esse mundo digital, acessar essa rede para se comunicar com o mundo, acho que isso é uma habilidade (TI1). Essa afirmação coincide com o que diz Araújo (2019) em relação à percepção. No que diz respeito ao sentido de aprender ou aprendendo, os entrevistados compreendem que essa necessidade está relacionada à aprendizagem, e esta pode significar uma oportunidade de desenvolver as habilidades necessárias para sua inclusão na cultura digital, como podemos observar em uma das falas: Eu acho importante porque é uma habilidade prática e rápida para comunicação né (TI7). 
Observamos que navegar na internet amplia a visão do que vem a ser habilidades digitais para os participantes, embora, as questões técnicas estejam presentes, como relata um participante:

"Justamente eu estou aqui para aprender, visse, sei um pouquinho ligar e desligar, no tablet ainda não sei. (...) Ligo, desligo, no Zap já mando mensagem, recebo mensagem, agora as outras coisas ainda tô aprendendo" (TI2)

“(...) acho que a gente tem que aprender alguma coisa para não ficar tão no passado, é por isso” (TI5).

Neste sentido, é preciso entender o que diz Perrenoud $(1999,2013)$ sobre as habilidades. Para o autor, as habilidades orientam operações mentais e concretas podendo se constituir de várias competências, ou seja, é necessário refletir também sobre a apropriação crítica dessas tecnologias. Nesse contexto, os participantes percebem algumas habilidades digitais, de forma diferente, mas não isolada, corroborando o que nos diz Araújo (2019), no decorrer das entrevistas como: Acessar (TI1); Passar mensagem (...) como faz uma ligação (TI2); Pesquisa no Google, Praticar (TI3); Manusear o aparelho, jogos para distrair (TI5); Eu penso todas né, porque o idoso esquece muito (...) enviar (TI7).

Como podemos observar, são respostas que representam um conjunto de ações relacionadas às habilidades digitais como operacionalização, ou seja, como saber fazer, podendo ser alocadas nessa categoria. Esses dados nos revelam que, apesar de saberem utilizar pouco a rede para se comunicar, os respondentes reconhecem que desenvolver essas habilidades é muito enriquecedor na busca por informações e na melhoria da qualidade de vida, sobretudo em situações de lazer e entretenimento. Nesse processo, ao dizer que $o$ idoso esquece muito (...) (TI7), podemos inferir que possivelmente essa dificuldade pode estar relacionada ao processo de envelhecimento referente às dificuldades que surgem devido ao avanço da idade.

Perguntamos aos participantes sobre "Quais as principais dificuldades/problemas para utilizar o smartphone?". Eles responderam:

\footnotetext{
"Eu não senti tanta dificuldade" (TI1)

"Aprendi a ligar, enviar mensagem, as outras coisas não sei não. Tô aprendendo" (TI2)
}

"Olha, a principal foi ligar o bicho, ligar, falar (...)" (TI 4) 
"Muitas, eu pego assim hoje em dia, vou te contar, até pra tocar e ligar eu acho dificil e pra mexer é pior (...)" (TI5)

"Eu sinto dificuldades. Agora mesmo esse final de semana foi um desastre" (TI6)

Observamos que a maioria dos participantes revela sentir dificuldades em utilizar o smartphone, tanto nas funções mais básicas, como nas funções relacionadas à internet. Mas essas dificuldades não os impedem de utilizar o smartphone. Isso indica que essas dificuldades estão relacionadas, muitas vezes, à falta de conhecimento para utilizar o dispositivo, ou seja, relacionadas ao saber fazer. É o que Kachar (2003) ressalta sobre a dificuldade de entender a linguagem.

Ainda sobre essas dificuldades, indagamos "Você tem recebido ajuda dos familiares ou amigos em relação ao uso do smartphone?". Eles responderam:

\footnotetext{
"Meus vizinhos e meus amigos" (TI1)

“Olha, eu pergunto só aos filhos" (TI2)

"Não, não, são horríveis, nem gostam e nem adianta eu pedir, não têm paciência" (TI3)

"Você chega para um filho e pergunta, por exemplo, como é que eu vou ver a minha... o meu saldo, a minha conta? Mas, ah mamãe! A senhora não estuda, vá, faça. Aí você já fica inibido de voltar e perguntar (...)” (TI4)
}

"O pouco que eu sei é com minhas filhas, assim com os amigos não (...)" (TI5)

Observamos que a maioria dos participantes não gosta de pedir ajuda à família e aos amigos. Menos da metade gosta de pedir aos familiares e poucos preferem ajuda do curso.

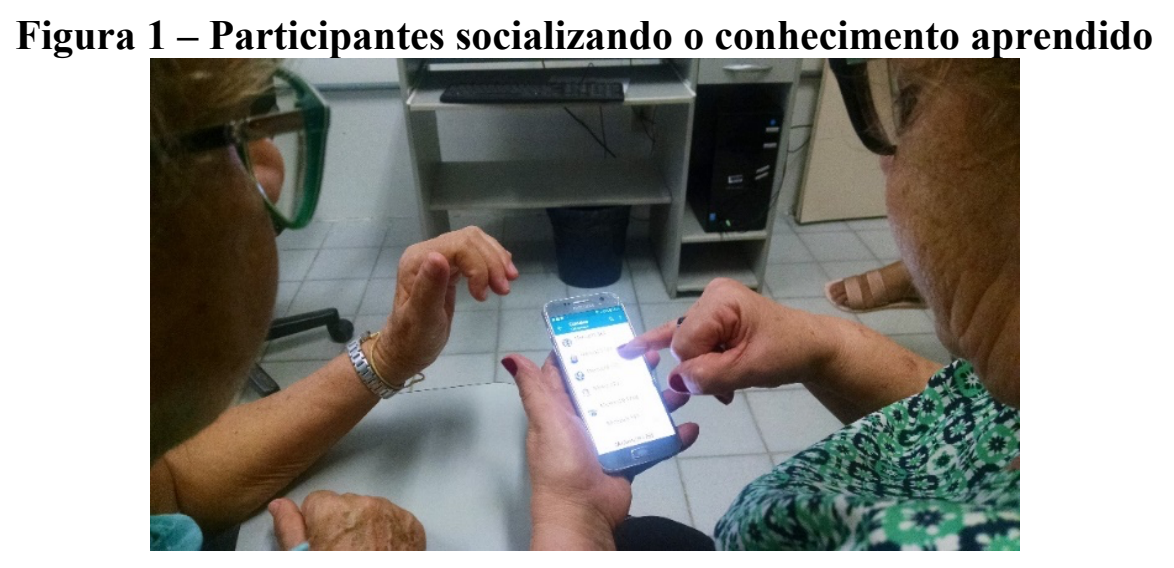

Fonte: Narrativa fotográfica própria, 2019. 
Ainda questionamos se esse público considerava que o uso dessa tecnologia tem ajudado a resolver situações/problemas em seu cotidiano e, em caso positivo, que relatassem as situações.

"Tem, tem me ajudado muito. Agora não me ajuda nesse negócio de banco e eu sou doida (...)" (TI1)

“(...) Eu falo com meus filhos: preciso de alguma coisa na farmácia, água, tudo isso eu uso o celular, médico, marcação de consulta, banco, banco não" (TI2)

"Tem sim, tem. Eu acho que pra mim eu acho que é mais no sentido de comunicação. Não é? com o WhatsApp" (TI3)

"Não me ajuda não. Nadinha. Pra falar a verdade pode ser que seja uma deficiência minha, né?" (TI5)

"100\%. A pessoa tá longe de casa quer uma comunicação, vou dizer, é na hora (...) É muito bom" (TI7).

Observamos pelos dados que a maioria dos participantes considera que o uso das tecnologias digitais tem ajudado a resolver situações em seu cotidiano. Um entrevistado considerou negativa essa ajuda. Percebemos um considerável índice de ocorrência nas falas em relação à comunicação, relacionada à nova forma de interação social, como ressalta Lemos (2009).

Com relação à unidade banco, para alguns participantes esse uso ainda é um desafio. Isso pode indicar que essas pessoas, por apresentarem certas dificuldades com os terminais eletrônicos dos bancos, são estigmatizadas.

Quando questionados sobre o que pensam a respeito da inclusão digital na terceira idade (Quadro 2), os participantes responderam:

Quadro 2 - Perspectiva dos participantes sobre inclusão digital

\begin{tabular}{|c|c|c|c|c|}
\hline $\begin{array}{c}\text { Objetivo } \\
\text { Específico }\end{array}$ & Categoria & Subcategoria & $\begin{array}{l}\text { Unidades de } \\
\text { Registro }\end{array}$ & $\begin{array}{l}\text { Unidades de } \\
\text { Contexto }\end{array}$ \\
\hline \multirow{2}{*}{$\begin{array}{l}\text { Verificar a } \\
\text { percepção das } \\
\text { pessoas da } \\
\text { terceira idade } \\
\text { sobre as } \\
\text { habilidades } \\
\text { digitais } \\
\text { necessárias } \\
\text { para sua } \\
\text { inclusão na } \\
\text { cultura digital }\end{array}$} & \multirow{2}{*}{ Pertencimento } & \multirow{2}{*}{$\begin{array}{l}\text { Sentimento } \\
\text { positivo }\end{array}$} & $\begin{array}{l}\text { faixa } \\
\text { etária/pessoa } \\
\text { de } \\
\text { idade/idoso }\end{array}$ & $\begin{array}{l}\text { “(..) acho que coisas novas aparecem } \\
\text { para essa faixa etária que está hoje } \\
\text { muito, como se dizer, tá muito mais } \\
\text { valorizado do que anos atrás } \\
\text { entendesse? hoje tem mais respeito } \\
\text { (...)” (TII) }\end{array}$ \\
\hline & & & $\begin{array}{l}\text { bom } \\
\text { mundo } \\
\text { dificuldade }\end{array}$ & $\begin{array}{l}\text { "É bom, é bom, sabe por quê? porque } \\
\text { a gente não precisa de tá pedindo as } \\
\text { coisas ao povo a ninguém aliás, ao } \\
\text { povo não a ninguém (...) A pessoa de } \\
\text { idade não tem muita paciência para } \\
\text { esperar então a gente tá aprendendo é } \\
100 \% \text { tudo melhor, com certeza." (TI2) }\end{array}$ \\
\hline
\end{tabular}




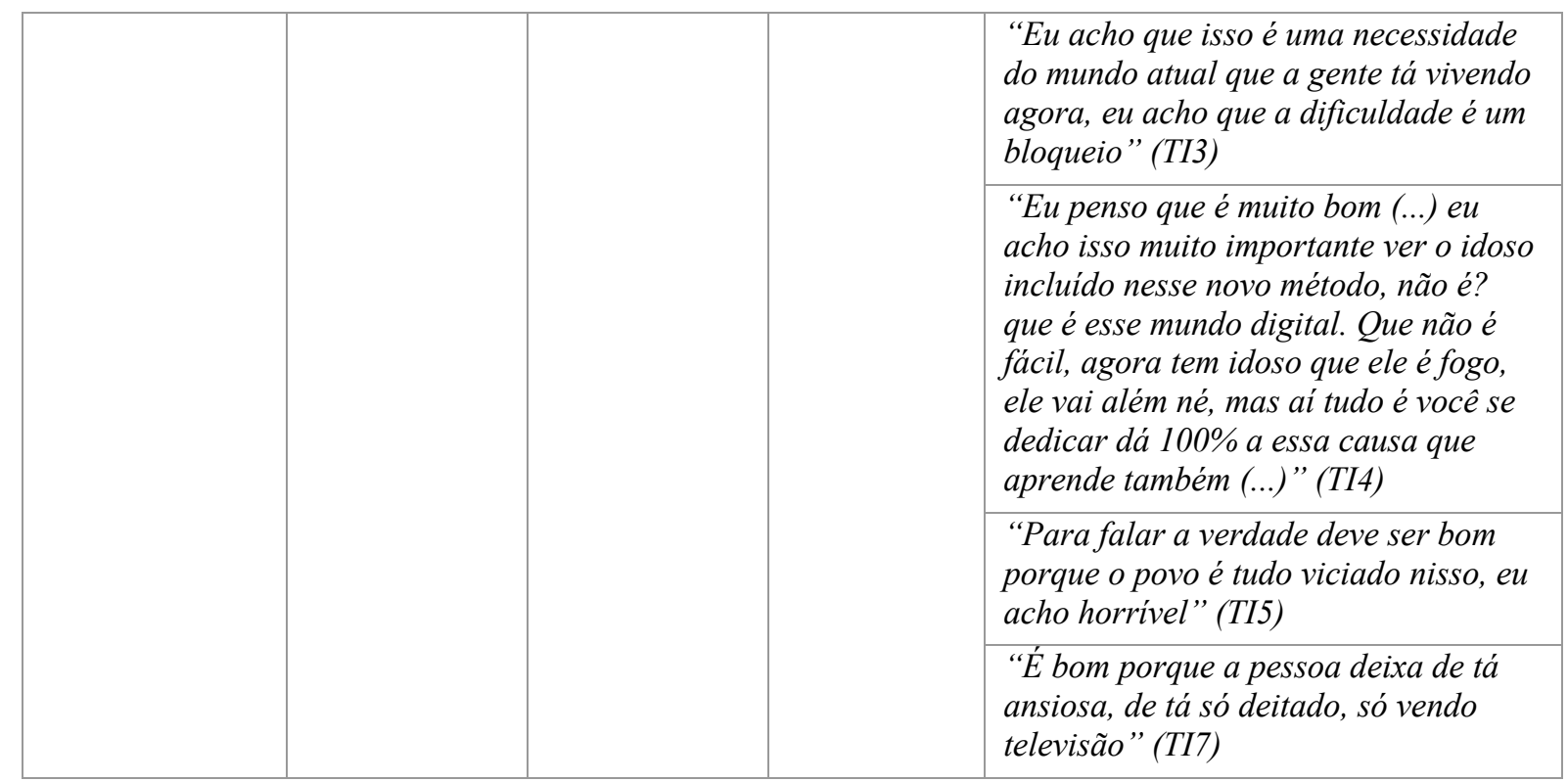

Fonte: Elaboração própria, 2019.

Podemos identificar que a perspectiva de inclusão digital para os participantes aparece de maneira implícita. A palavra bom pode caracterizar para essa faixa etária ou pessoa de mais idade ou idoso um sentimento positivo de pertencer ao mundo digital. Observamos em uma das respostas que a perspectiva de inclusão digital na terceira idade é estar incluído nesse novo método (...) (TI4). Outro, diz que é uma necessidade do mundo atual. A maioria dos participantes acredita que a inclusão digital pode favorecer o bem-estar quando se estabelecem conexões entre os indivíduos. Esse sentimento positivo pode indicar que a inclusão digital se torna relevante, como relata um participante sobre ficar ansiosa (TI7). Inferimos que elementos de ordem cognitiva, emocional e social são considerados importantes pelos participantes nesse processo. Isso aponta para a dimensão social. No que se refere ao social, é preciso refletir sobre a inserção social das ferramentas digitais, para que esta não se constitua como fator de exclusão social (CAZELOTO, 2008).

Nesta direção, questionamos aos respondentes se eles se consideram inclusos digitalmente. Eles responderam:

"Nem tanto. Porque tem algumas coisinhas que a gente não domina" (TI1)

"Eu me sinto, me sinto. Porque além de saber um pouquinho ai eu já vou procurar mais pra aprender, estudar mais" (TI2)

"Pouco. Eu quero até repetir o curso" (TI3)

"Muito, muito, muito, muito bom saber como que é uma oportunidade de você dizer assim poxa eu existo. Eu também sou capaz, eu faço parte desse mundo, eu estou incluida nesse mundo (...)" (TI4) 
"Por enquanto ainda não, eu me sinto excluída." (TI5)

"Sim. E se tivesse uma apostila seria melhor (...)” (TI6)

"Sinto. Dá para conversar com as pessoas né” (TI7).

Observamos poucas unidades comuns existentes nas respostas. No entanto, 3 participantes se sentem incluídos digitalmente; outro, nem tanto. Apenas 1 afirmou que se sente um pouco incluído e 1 se sente excluído. Alguns participantes relatam que o domínio de certas habilidades desperta um sentimento positivo. Isso faz com que os participantes se sintam capazes de participar da cultura digital e aprender as habilidades necessárias para sua inclusão. Podemos inferir que o fato dos participantes da pesquisa usarem as tecnologias, mesmo que de forma limitada, essa prática representa, para esses indivíduos, a dimensão técnica da inclusão digital. Esses dados nos permitem concordar com Kachar (2003), com relação à necessidade dessas pessoas se sentirem incluídas, conectadas ao mundo moderno.

Destacamos nestas categorias que os participantes da pesquisa têm a percepção de habilidades digitais relacionadas à forma de saber usar a tecnologia, na busca de informações em diferentes situações, ou seja, essa percepção está relacionada ao saber fazer e ao pertencimento à cultura digital, sobretudo, em situações de lazer e entretenimento.

\section{Consideração finais}

Podemos dizer, diante do estudo realizado, que a percepção das pessoas da terceira idade sobre as habilidades digitais desenvolvidas para a sua inclusão no mundo digital tem relação com as possibilidades de comunicação e interação em seu convívio social. Os participantes percebem as habilidades digitais e sabem utilizá-las em diversas situações conforme suas necessidades.

É importante salientar que as pessoas que estão na terceira idade estão tentando desenvolver habilidades associadas às suas necessidades, para vencer os desafios da cultura contemporânea. Embora o uso das tecnologias favoreça o acesso à comunicação e interação, tal uso acontece de forma limitada, muitas vezes, devido ao processo de envelhecimento.

Considerando que o objetivo do estudo foi alcançado, os resultados forneceram indicativos importantes para reflexão de como as habilidades digitais vêm sendo percebidas pelas pessoas de mais idade, uma vez que o entendimento dessas habilidades digitais para os participantes da pesquisa representa a dimensão técnica da inclusão digital.

Neste sentido, consideramos ainda que essa percepção vai além de conhecer as 
técnicas para o manuseio das tecnologias. Ela está relacionada ao saber fazer, podendo contribuir na busca de informações em diferentes situações, sobretudo, em situações de lazer e entretenimento.

\section{Referências}

ARAÚJO, J. P. M. de. A teoria da percepção de John R. Searle. 2019. Tese (Doutorado em Filosofia) - Universidade Federal de Pernambuco, Recife, 2019. Disponível em: https://repositorio.ufpe.br/handle/123456789/35997

BRASIL. Lei $\mathbf{n}^{\mathbf{0}} \mathbf{1 0 . 4 7 1}$ de 01 outubro de 2003. Cria o Estatuto do Idoso. Disponível em: http://www2.senado.leg.br/bdsf/bitstream/handle/id/530232/estatuto_do_idoso_1ed.pdf. Acesso em: 05 ago. 2018.

CAZELOTO, Edilson. Inclusão digital: uma visão crítica. São Paulo: Senac, 2008.

DEBERT, Guita Grin. Velho, terceira idade, idoso ou aposentado? Sobre diversos entendimentos acerca da velhice. Revista Coletiva. Número 05. Julho/Agosto/Setembro de 2011. Disponível em: https://pt.scribd.com/document/371812394/Guita-Grin-Debert-VelhoTerceira-Idade-Idoso-Ou-Aposentado-Revista-Coletiva-2011. Acesso em: 17 nov. 2018.

GANDRA, T. K. Inclusão digital na Terceira Idade: um estudo de usuários sob a perspectiva fenomenológica. 2012. Dissertação (Mestrado em Ciência da Informação) Universidade Federal de Minas Gerais, 2012. Disponível em:

http://www.bibliotecadigital.ufmg.br/dspace/bitstream/handle/1843/ECID-

8XLKLJ/disserta_o_tatiane_gandra_2012.pdf?sequence=1. Acesso em: 03 ago. 2018.

INSTITUTO BRASILEIRO DE GEOGRAFIA E ESTATÍSTICA (IBGE). Projeção da População 2018. Disponível em: https://biblioteca.ibge.gov.br/index.php/bibliotecacatalogo?view=detalhes\&id=2101597. Acesso em: 12 nov. 2018.

KACHAR, Vitória. Terceira Idade \& Informática: aprender revelando potencialidades. São Paulo: Cortez, 2003.

KENSKI, Vani Moreira. Educação e tecnologias: o novo ritmo da informação. 8. ed. Campinas, SP: Papirus, 2012.

LEMOS, A. Infraestrutura para a cultura digital. In: SAVAZONI, R.; COHN, S. (Orgs.). Cultura digital.br. Rio de Janeiro: Azougue Editorial, 2009.

MORAES, Roque. Análise de Conteúdo. Educação. Santa Maria, Ano XXII, n. 37, pp. 7-31, 1999.

MORIN, Edgar. Os sete saberes necessários à educação do futuro. 8. ed. São Paulo: Cortez; Brasília: UNESCO, 2011. 
PERRENOUD, Philippe. Construir as competências desde a escola. Porto Alegre: Artes Médicas Sul, 1999.

PERRENOUD, Philippe. Desenvolver competências ou ensinar saberes? A escola que prepara para a vida. Porto Alegre: Penso, 2013.

SILVA, W. A. da; KALHIL, J. Barrera. Um estudo sobre as habilidades necessárias para utilização das tecnologias digitais como recurso metodológico. Revista REAMEC, Cuiabá MT, v. 5, n.1, 2017. Disponível em: http://periodicoscientificos.ufmt.br/ojs/index.php/reamec. Acesso em: 09 jan. 2019.

UNESCO. Organização das Nações Unidas para a Educação, a Ciência e a Cultura. Educação para a cidadania global. 2015. Disponível em:

https://unesdoc.unesco.org/ark:/48223/pf0000234311. Acesso em: 26 jan. 2019. 